\title{
Nanocrystal Formation in Aqueous Insertion Polymerization
}

\author{
Alexandra Godin, ${ }^{\circledR}$ Inigo Göttker-Schnetmann, and Stefan Mecking*(i) \\ Chair of Chemical Materials Science, Department of Chemistry, University of Konstanz, 78464 Konstanz, Germany
}

Supporting Information

ABSTRACT: High molecular weight linear polyethylene, in the form of $7 \mathrm{~nm}$ thin single-lamella nanocrystals with a diameter of up to $200 \mathrm{~nm}$, is generated via aqueous catalytic polymerization using the water-soluble catalyst precursor $\left[\kappa^{2}\right.$ $\mathrm{N}, \mathrm{O}-\left\{2,6-\left(3^{\prime}, 5^{\prime}-\left(\mathrm{F}_{3} \mathrm{C}\right)_{2} \mathrm{C}_{6} \mathrm{H}_{3}\right)_{2} \mathrm{C}_{6} \mathrm{H}_{3}-\mathrm{N}=\mathrm{C}(\mathrm{H})-\left(3,5-\mathrm{I}_{2}-2-\mathrm{O}-\right.\right.$ $\left.\left.\left.\mathrm{C}_{6} \mathrm{H}_{2}\right)\right\} \mathrm{NiCH}_{3}\left\{\mathrm{P}\left(3-\mathrm{C}_{6} \mathrm{H}_{4} \mathrm{SO}_{3} \mathrm{Na}\right)_{3}\right\}\right]$ (1-TPPTS). Studies under true pressure reactor conditions using a ${ }^{13} \mathrm{C}$-labeled catalyst precursor $1-{ }^{13} \mathrm{C}$-TPPTS show that in the first $30 \mathrm{~s}$, $21-28 \%$ of the catalyst precursor initiates polymer chains. Catalyst deactivation occurs preferentially by hydrolysis,

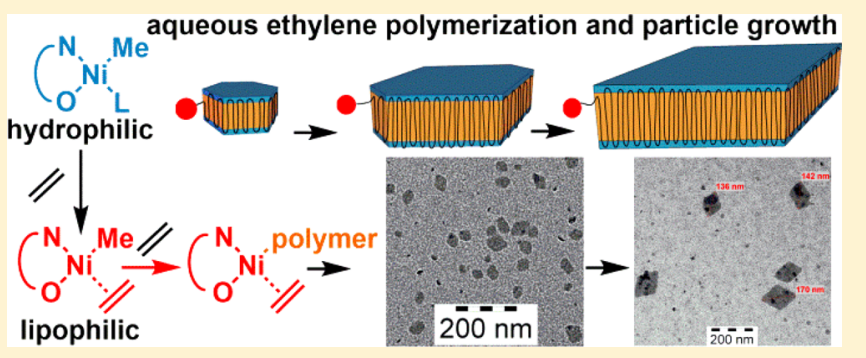
resulting in the formation of fully saturated polyethylene chains. The catalyst lifetime can be extended for more than $10 \mathrm{~h}$ upon addition of weakly coordinating compounds like $\mathrm{N}, \mathrm{N}$-dimethylformamide. Alternatively, at strongly basic conditions ( $\mathrm{pH}$ 12.5) nanoparticle dispersions consisting of polyethylene with molecular weight of up to $M_{\mathrm{n}}=7 \times 10^{5} \mathrm{~g} \mathrm{~mol}^{-1}$ and $M_{\mathrm{w}} / M_{\mathrm{n}}=1.2$ are accessible after $60 \mathrm{~min}$ polymerization time. "Living"-type polymerization also can be performed by substituting water with deuterium oxide as the reaction medium. Here, catalyst lifetimes of more than $24 \mathrm{~h}$ are observed, and dispersions with more than $20 \mathrm{wt} \%$ nanocrystals are accessible at turnover frequencies (TOF) of $\sim 4000$ ethylene (catalyst precursor) $)^{-1} \mathrm{~h}^{-1}$. A pressurizable sampling chamber was used to draw samples at high pressure and enabled the in-depth analysis and monitoring of the polymerization reaction and the particle formation in a time range of $30 \mathrm{~s}-24 \mathrm{~h}$. It was shown that under most reaction conditions studied each nickel center produces one single-chain polyethylene particle, and the diameter of the resulting nanoplatelet is determined by the molecular weight of the polyethylene chain.

\section{INTRODUCTION}

Aqueous polymer dispersions are widely applied as paints or adhesives, being an environmentally friendly alternative to products which contain organic solvents. Such dispersions are generally produced by free radical emulsion polymerization which restricts the number of accessible polymers. The formation of the particles and the polymerization mechanism are well understood, and a range of techniques exist to control the particle morphology. ${ }^{1-6}$ By contrast, catalytic polymerizations-which account for more than 100 million tons of polyolefin products annually ${ }^{7,8}$ - are not compatible with aqueous systems, and aqueous polyolefin dispersions based on catalytically obtained HDPE and LLDPE have so far been generated by secondary dispersion techniques. ${ }^{9,10}$ Alternatively, aqueous dispersions of linear hydrocarbon waxes may also be obtained by $\mathrm{C} 1$ polymerization of methyl ylides. ${ }^{11}$ A completely new approach for the generation of the polyolefin nanoparticle dispersions was reported by using water-soluble catalysts of type 1-L (Figure 1). ${ }^{12-15}$ Unlike medium and high pressure free radical emulsion polymerization of ethylene which yields $\mathrm{LDPE}^{16}$ the catalytic ethylene polymerization allows for the control of the polymer microstructure; consequentially, polymers inaccessible by free radical methods can be prepared. For example, using catalyst precursor 1-TPPTS in aqueous dispersion at $15^{\circ} \mathrm{C}$ and 40 bar ethylene (Figure 2), high molecular weight linear polyethylene $\left(M_{\mathrm{n}}=2 \times 10^{5} \mathrm{~g} \mathrm{~mol}^{-1}\right.$ and $\sim 6$ branches/1000 carbon atoms) was generated in the

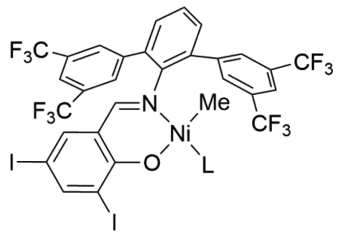

$1-\mathrm{L}$

Figure 1. Water-soluble $\mathrm{Ni}(\mathrm{II})$ complex active in ethylene polymerization. $\mathrm{L}=$ TPPTS $=$ sodium $3,3^{\prime}, 3^{\prime \prime}$-phosphinetriyltribenzenesulfonate.

unusual form of single lamella nanocrystals with diameters of $25.4 \pm 4.3 \mathrm{~nm}$ and a thickness of $6.3 \pm 0.8 \mathrm{~nm}^{17}$ In these experiments polymerization starts immediately, and deactivation results in polymer formation ceasing within $30 \mathrm{~min}$. The reasons for catalyst deactivation and the process by which the polymer nanoparticles are formed are barely understood to date. An understanding of this unique process is, however, of fundamental interest and also required to control particle morphologies.

Received: September 8, 2016

Revised: November 16, 2016

Published: December 2, 2016 


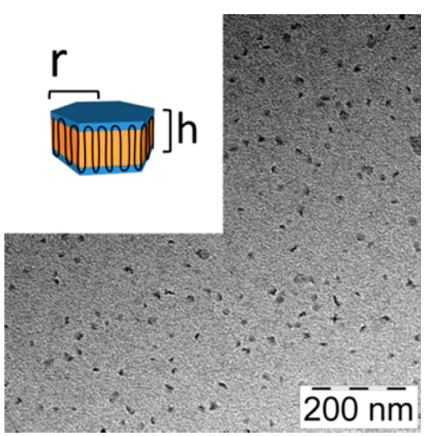

Figure 2. TEM micrograph of a polyethylene nanodispersion and a sketch of a typical polyethylene particle with diameter $d=2 r$ and particle thickness $h$ obtained by catalytic aqueous ethylene polymerization.

We now report insights into nanoscale processes like particle formation and growth as well as related molecular mechanisms of catalyst activation and deactivation.

\section{RESULTS AND DISCUSSION}

In order to address particle formation, a prerequisite is a knowledge of the fate of the catalysts precursor. To date, it is entirely unclear to what extent active species are formed in the synthesis of nanocrystals. We have previously studied the activation of 1-DMSO in DMSO as a solvent in a NMR experiment at $55{ }^{\circ} \mathrm{C}$ and reported that the activation of the catalyst precursor takes place via the displacement of the labile ligand by the monomer at rates of $\sim 10^{-4} \mathrm{~s}^{-1}$.

Differently to polymerization in the organic solvent, using 1TPPTS in water, the dissociation of the water-soluble TPPTS ligand of the catalyst precursor is also strongly connected to the transformation of the water-soluble catalyst precursor into a water-insoluble species. In $\mathrm{D}_{2} \mathrm{O} / \mathrm{SDS}$ solution or in DMSO even without ethylene addition the TPPTS ligand easily dissociates, while remaining coordinated under otherwise identical conditions in solvents like methanol. ${ }^{12}$ The exact nature of the obtained (lipophilic) nickel species was not elucidated.

A polymerization performed under standard conditions (15 ${ }^{\circ} \mathrm{C}$ and 40 bar ethylene $)^{19}$ for $30 \mathrm{~min}$ but with an excess of the free TPPTS ligand, which would potentially increase the concentration of undissociated 1-TPPTS, showed that excess TPPTS had only a minor influence on the catalyst productivity (for details cf. Supporting Information, Table S1). In order to study the stability of this $\mathrm{Ni}$ species in the aqueous solution, which is typically applied in pressure reactor experiments under the corresponding conditions, we pre-exposed the catalyst precursor 1-TPPTS to aqueous surfactant solution for $0.5-2 \mathrm{~h}$ prior to polymerization (for details cf. Figure 3 and Supporting Information).

When 1-TPPTS was exposed to the surfactant solution for $30 \mathrm{~min}$ prior to polymerization, almost no deactivation of the catalyst precursor was observed. The particles thus obtained were similar in size and appearance compared to the particles which are obtained without pre-exposure of the catalyst precursor (cf. Figure 3 and Figure S4d). On the other hand, exposure of 1-TPPTS to the surfactant solution for $2 \mathrm{~h}$ prior to polymerization resulted in the complete deactivation of the catalyst precursor, as concluded from a lack of polymer formation.

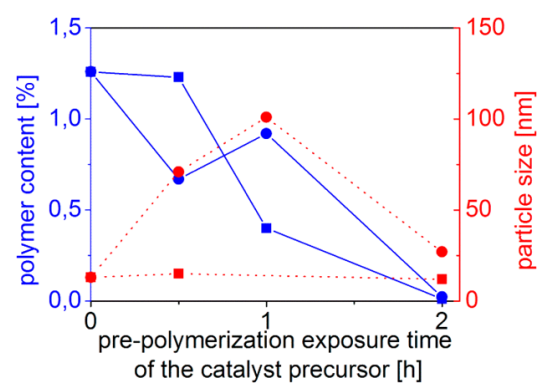

Figure 3. Catalyst stability in water. $10 \mu \mathrm{mol} \mathrm{L} \mathrm{L}^{-1}$ of catalyst precursor solution was stirred together $(\boldsymbol{\square})$ or without $(\mathbf{0})$ SDS inside the reactor at $15{ }^{\circ} \mathrm{C}$. Prior to polymerization, SDS was added to the solutions which were stirred without surfactant. The polymerization was carried out for $30 \mathrm{~min}$ at 40 bar ethylene, $15{ }^{\circ} \mathrm{C}$.

We performed a second set of experiments by pre-exposing the catalyst precursor to water and adding the surfactant just before the polymerization. Here, after $2 \mathrm{~h}$ the catalyst precursor was also completely deactivated. Apparently, the presence of the surfactant micelles does not significantly affect the stability of the catalyst precursor. On longer reaction times it is the aqueous environment that obviously promotes the decomposition of the catalyst precursor or the species derived thereof after TPPTS dissociation.

Interestingly, when 1-TPPTS was pre-exposed to water for $30 \mathrm{~min}$ and the surfactant was added just before charging with ethylene, the dispersion obtained after polymerization for 30 min, i.e., with low polymer content, consisted of a mixture of small hexagonal and (very) large $(\sim 200 \mathrm{~nm})$ lozenge shaped particles (Figure $\mathrm{S} 4 \mathrm{a}-\mathrm{c}$ ). We suggest that without being stabilized by micelles some kind of aggregated nickel species forms, which, once formed, does not easily separate upon surfactant addition. These $\mathrm{Ni}$ species, which are active in polymerization, are situated in close proximity to each other, and the polyethylene chains generated from such "aggregates" will likely crystallize as one particle; thus, very large particles can be generated (possible mechanisms of the particle formation are discussed below). The large particle surface can be stabilized by the surfactant present during the polymerization and distinct thin lamellae are obtained. For comparison, in polymerizations without any surfactant large, multilamellar particles were obtained and the polymer yield was low (Figure S5). We suggest that without stabilization by surfactant the generated polyethylene chains ultimately form more spherical, multilamellar particles in order to reduce the surface energy of the highly hydrophobic crystals.

Catalyst Activation. A knowledge of the degree of activation of the catalyst precursor is of particular importance for estimation of its performance. However, until now, the degree of activation of 1-TPPTS is unknown. In this work the degree of activation of the catalyst precursor was determined for the first time under true pressure reactor conditions using ${ }^{13}$ C-labeled 1-TPPTS $\left(1-{ }^{13} \mathrm{C}\right.$-TPPTS) (Scheme 1 ; for details like NMR spectra or catalytic activity cf. Supporting Information, pp S11 ff). According to the insertion polymerization mechanism, the ${ }^{13} \mathrm{C}$-label is incorporated at the end of the polymer chain and can be identified as part of the S1 signal via ${ }^{13} \mathrm{C} \mathrm{NMR}{ }^{20,21}$ Under true-pressure reactor conditions the catalyst derived from 1-TPPTS is a highly active polymerization catalyst; that is, the catalytically active sites produce high molecular weight polymer chains in a short time. However, in order to obtain a sufficient ${ }^{13} \mathrm{C}$-end group label concentration 
Scheme 1. Polymerization of Ethylene with ${ }^{13} \mathrm{C}$-Labeled Complex $1{ }^{13} \mathrm{C}_{\text {-TPPTS }}{ }^{a}$

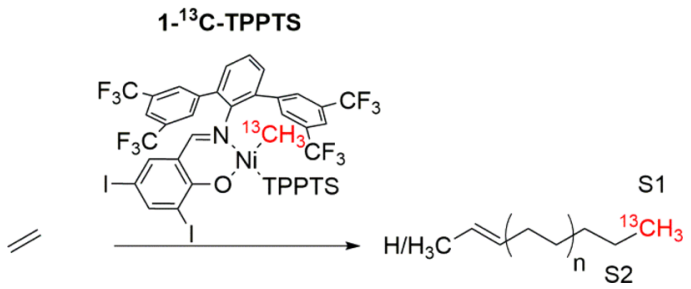

${ }^{a} \mathrm{C}$ atoms assigned as $\mathrm{S} 1$ and $\mathrm{S} 2$ in the ${ }^{13} \mathrm{C}$ NMR spectra are marked.

for the NMR analysis, degrees of polymerization must not be too high. A certain range exists, where a sufficient amount of polymer is formed, and at the same time its molecular weight is low enough for the identification of the end-groups by ${ }^{13} \mathrm{C}$ NMR. Such a polymer was obtained by aqueous ethylene polymerization under standard conditions using $1-{ }^{13} \mathrm{C}$-TPPTS followed by venting the reactor after $\sim 30 \mathrm{~s}$ and immediate precipitation in methanol, which ensures instantaneous quenching of the active species (Table 1).

The samples were analyzed by high temperature ${ }^{1} \mathrm{H}$ and ${ }^{13} \mathrm{C}$ NMR spectroscopy, and at first instance, the degree of activation was calculated from ${ }^{13} \mathrm{C}$ NMR spectra assuming that each chain possesses only one saturated chain end. Under this assumption, and according to $\left(n_{\mathrm{PE} \text { chains }}[\mathrm{mol}] \times\right.$ portion of saturated labeled chain ends $[\%]) / n_{\text {catalyst precursor }}[\mathrm{mol}]$ (for calculation details cf. Supporting Information eqs S1-S7) ca. $4 \%$ of the ${ }^{13} \mathrm{C}$-labels were incorporated into the polymer as chain end groups after $30 \mathrm{~s}$ polymerization time (Table 1, column 8).

However, the calculated fractions of polymer-initiating precatalyst (Table 1, column 8) are likely higher based on further observations:

(a) The ratio of aliphatic end groups:olefinic groups is far from expected 1:1 (for terminal olefins) or 2:1 (for internal olefins) and reaches e.g. 50:1 for entry 1-9 (Figure S22, also cf. Figure 4). This observation indicates that chain transfer after $\beta$ hydride elimination is negligible under these polymerization conditions. The absence of olefinic groups in the polymer thus indicates that either the polymer chain is still attached to the nickel catalyst or that irreversible catalyst deactivation prior to

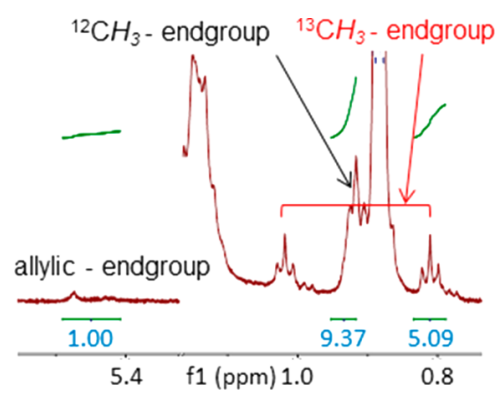

Figure 4. Olefinic region and $\mathrm{CH}_{3}$ region of the ${ }^{1} \mathrm{H}$ NMR spectrum $\left(403 \mathrm{~K}\right.$ in $\mathrm{C}_{2} \mathrm{D}_{2} \mathrm{Cl}_{2}$ ) of polyethylene obtained with $1{ }^{13} \mathrm{C}$-TPPTS in a reactor polymerization after $30 \mathrm{~s}$ at standard conditions (from entry 12 , Table 1, the ratio of olefinic:saturated end group is ca. 1:20).

$\beta$-hydride elimination has occurred. While we can exclude the presence of polymer chains still attached to nickel centers in the high-temperature NMR experiments, two irreversible catalyst deactivation reactions may account for the lack of olefinic groups in the polymer in the absence of chain transfer: (1) protonolysis reaction of a nickel polymeryl species with water ${ }^{22}$ or during work-up with methanol, to generate fully saturated polymer chains and (2) bimolecular reductive coupling of two nickel alkyl species to generate fully saturated polymer chains (Scheme 2).

We will provide strong indication/evidence that protonolysis of nickel polymeryl species by water is indeed an important deactivation pathway for polymerizations in aqueous media (vide infra). Such protonolysis reaction (in the absence of chain transfer) would result in a 50:50 ratio of ${ }^{13} \mathrm{C}$-labeled and unlabeled methyl end groups in the polymer, while the bimolecular coupling results in $100 \%{ }^{13} \mathrm{C}$-labeled methyl end groups.

(b) Experimentally, we have determined $9-25 \%$ of ${ }^{13} \mathrm{C}$ labeled methyl end groups (Table 1 , column $7,{ }^{13} \mathrm{C}$ NMR based) despite the absence of chain transfer and not even matching the expected lower limit of $50 \%$ in the case of protonolysis. The most convincing rational for such deviation of the found ${ }^{13} \mathrm{C}$-label in the methyl end groups is that extensive chain walking transports part of the ${ }^{13} \mathrm{C}$-label into the polymer backbone (Scheme 3), which by the algorithms (cf. Table 1 , footnotes $\mathrm{f}, \mathrm{g}$ ) used here only apparently lowers the

Table 1. Short Time Experiments with ${ }^{13} \mathrm{C}$-Labeled Complex $1-{ }^{13} \mathrm{C}-\mathrm{TPPTS}$

\begin{tabular}{|c|c|c|c|c|c|c|c|c|c|}
\hline entry & $\begin{array}{c}(2) 1^{-13} \mathrm{C}- \\
\text { TPPTS }[\mu \mathrm{mol}]\end{array}$ & $\begin{array}{l}\text { (3)rctn } \\
\text { time }[\mathrm{min}]\end{array}$ & $\begin{array}{l}(4) \mathrm{PE} \\
{[\mathrm{mg}]}\end{array}$ & $\begin{array}{l}(5) M_{\mathrm{n}}^{\mathrm{GPC}}\left[10^{3}\right. \\
\left.\mathrm{g} \mathrm{mol}^{-1}\right]\end{array}$ & $\begin{array}{c}(6) \\
n_{\mathrm{PE}}[\mu \mathrm{mol}]\end{array}$ & $\begin{array}{c}(7) \chi\left[{ }^{13} \mathrm{C}-\right. \\
\text { labeled-S1 }]^{e} \\
{[\%]}\end{array}$ & $\begin{array}{l}\text { (8)initiated } 1-13 \mathrm{C} \text { - } \\
\text { TPPTS }^{f}[\%]\end{array}$ & $\begin{array}{c}\text { (9)initiated } 1-{ }^{13} \mathrm{C}-\mathrm{TPPTS} \\
{[\%](\text { corrected) }}\end{array}$ & $\begin{array}{c}(10) \\
\text { branches/ } \\
\text { 1000C }\end{array}$ \\
\hline $1-1^{b}$ & 10 & 0.5 & 85 & n.e & n.e. & & n.e. & n.e. & n.e. \\
\hline $1-2$ & 10 & 0.5 & 14 & 6.7 & 2.1 & 20 & 4.2 & 21 & 8 \\
\hline $1-3^{c}$ & 10 & 1 & 13 & n.e. & n.e. & n.e. & n.e. & n.e. & n.e. \\
\hline $1-4^{c}$ & 10 & 30 & 1720 & n.e. & n.e. & n.e. & n.e. & n.e. & 2 \\
\hline $1-5$ & 20 & 0.5 & 52 & 11.1 & 4.7 & 15 & 3.5 & 23.4 & 9 \\
\hline $1-6$ & 20 & 0.5 & 44 & 7.9 & 5.6 & 15 & 4.2 & 27.8 & 11 \\
\hline $1-7$ & 20 & 2 & 192 & 20.9 & 9.2 & 9 & $>5(4.1)$ & 45.9 & 5 \\
\hline $1-8^{d}$ & 20 & 0.5 & trace & n.e. & n.e. & n.e. & n.e. & & n.e. \\
\hline $1-9^{d}$ & 20 & 2 & 39 & 10.0 & 3.9 & 25 & $>4(4.9)$ & 19.5 & 4 \\
\hline
\end{tabular}

${ }^{a} 26 \mathrm{mmol} \mathrm{L}{ }^{-1} \mathrm{SDS}, 200 \mathrm{~mL}$ of water, $15{ }^{\circ} \mathrm{C}, 40$ bar. ${ }^{b}$ Unlabeled catalyst precursor 1-TPPTS. ${ }^{c}$ Slow depressurizing. ${ }^{d} 30 \mathrm{mmol} \mathrm{L}{ }^{-1} \mathrm{DMF} .{ }^{e}$ Estimated mol fraction $\chi$ according to eq $\mathrm{S} 4$ of the Supporting Information. For the accurate calculation of the signal ratios ${ }^{13} \mathrm{C}$ NMR spectra were used. Because of the strong tailing of the backbone signal, the integrals of the saturated end group and branch signals in ${ }^{1} \mathrm{H}$ NMR spectra are not quantitative. They provide qualitatively reliable information and were used for the estimation of the magnitude of the concentration of saturated and unsaturated end groups. ${ }^{f}\left(n_{\mathrm{PE}}[\mathrm{mol}] \times\right.$ labeled chain ends [\%])/ $n_{\text {catalyst precursor }}[\mathrm{mol}] ; n_{\mathrm{PE}}=$ mol of polyethylene formed. ${ }^{g}$ Corrected for absence of chain transfer: $m_{\mathrm{PE}}[\mathrm{g}] / M_{\mathrm{n}}\left[\mathrm{g} \mathrm{mol}^{-1}\right]=n_{\mathrm{PE}}[\mathrm{mol}] / n_{\text {catalyst precursor }}[\mathrm{mol}]$. 
Scheme 2. Irreversible Catalyst Deactivation Reactions Prior to Chain Transfer Resulting in Saturated to Unsaturated End Group Ratios $\gg 1: 1$

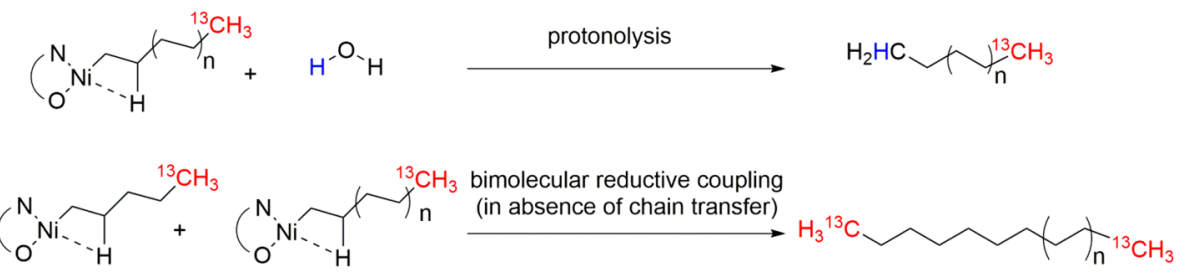

Scheme 3. In-Chain Incorporation of ${ }^{13} \mathrm{C}$-Label by Chain Walking Resulting in Less ${ }^{13} \mathrm{C}$-Labeled End Groups Than Expected

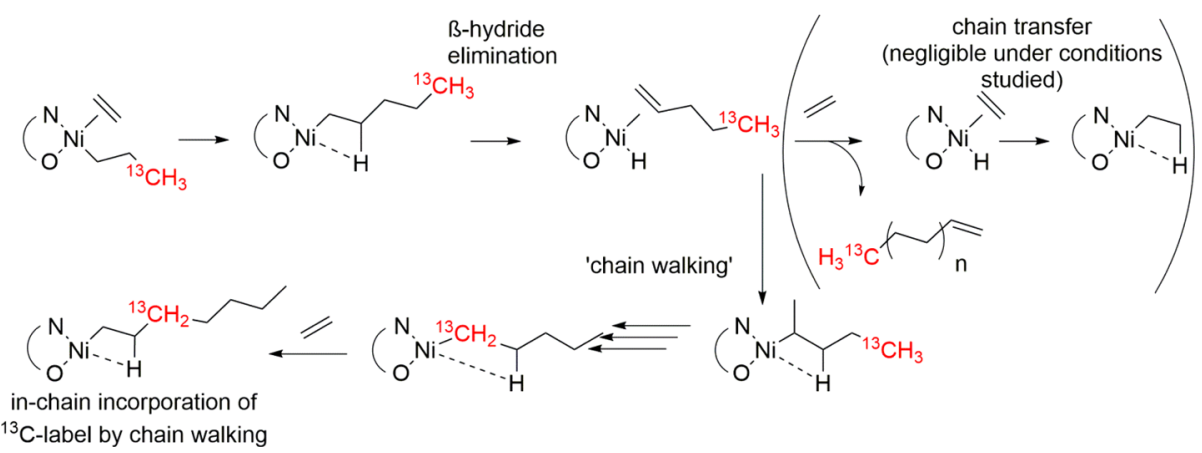

Scheme 4. Full Set of Possible Catalyst Deactivation Reactions under Standard Polymerization Conditions in the Presence of Proton Sources and of Chain Transfer

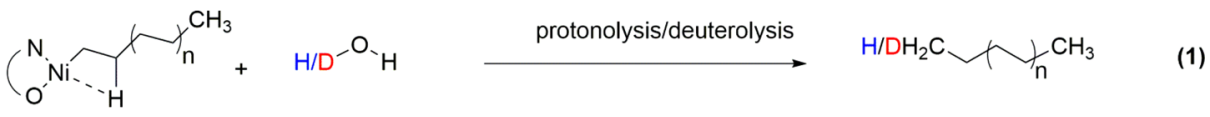

$$
\begin{aligned}
& \text { (in absence of chain transfer) }
\end{aligned}
$$

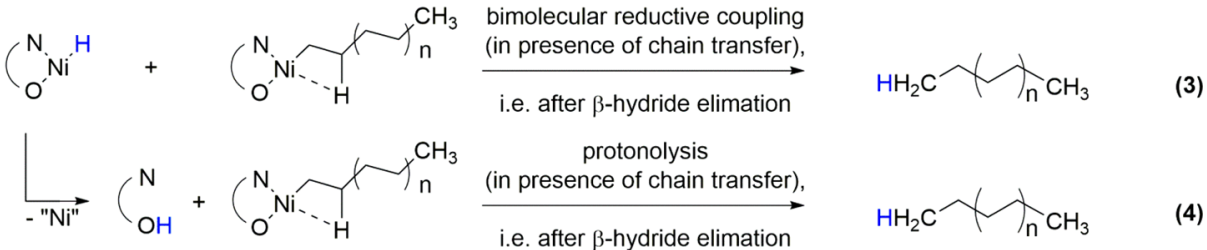

fraction of initiating catalyst precursors. Such chain walking is well-known in late transition metal polymerization catalysts, and it is clearly operative in the polymerizations studied here as evidenced by the occurrence of methyl (and ethyl) branches in the formed polymers (Table 1, column 10, and Figures S1522, S25).

The prevailing absence of chain transfer indicates that nearly every polymer chain is initiated by a ${ }^{13} \mathrm{C}$-labeled catalyst precursor. In consequence, the number of polymer chains $n_{\mathrm{PE}}=$ ( polymer yield $/\left(28 \mathrm{~g} \mathrm{~mol}^{-1} \times \mathrm{DP}_{\mathrm{n}}=\right.$ polymer yield $\left./ M_{\mathrm{n}}^{\mathrm{GPC}}\right)$ essentially equals the number of chain initiating catalyst precursors (Table 1, column 9), while deviations of the fraction of ${ }^{13} \mathrm{C}$-labeled vs unlabeled saturated methyl end groups are based on catalyst deactivation and chain walking. With this in mind, the fraction of precatalyst which initiates ethylene polymerization $\left(=n_{\mathrm{PE}}[\mathrm{mol}] / n_{\text {catalyst precursor }}[\mathrm{mol}]\right)$ reaches $21-$ $28 \%$ after $0.5 \mathrm{~min}$ polymerization time (Table 1 , column 9 entries 1-2, 1-5, and 1-6) and ca. 45\% after $2 \mathrm{~min}$ polymerization time (Table 1 , column 9 , entry 1-7).
Catalyst Deactivation. While in the absence of chain transfer reaction as e.g. in short time polymerizations of Table 1 indication for catalyst deactivation by hydrolysis (Scheme 2 and Scheme 4, line 1) instead of bimolecular alkyl-alkyl coupling was found (Scheme 2 and Scheme 4, line 2; vide supra), an additional deactivation reaction may operate under chain transfer conditions. Berkefeld et al. have shown in NMR experiments ${ }^{18}$ that nickel hydride species formed after ethylene insertion into $\mathbf{1 - d m s o}$ and $\beta$-hydride elimination rapidly undergo bimolecular reductive coupling with nickel alkyl complexes to form saturated hydrocarbons in $\mathrm{DMSO} / \mathrm{D}_{2} \mathrm{O}$ mixtures (Scheme 4, line 3) while the respective deuterolysis of nickel alkyls with $\mathrm{D}_{2} \mathrm{O}$ is slow in comparison (Scheme 4, line $1)$.

In addition, Brookhart et al. and Grubbs et al. have outlined that for similar anilidotropone nickel and salicylaldiminato nickel complexes protonated ligand forms by reductive elimination from the nickel hydride complex which then protonates the nickel alkyl bond to form saturated hydrocarbons (Scheme 4, line 4). ${ }^{23,24}$ Note that all these deactivation 
reactions produce one fully saturated hydrocarbon per deactivated nickel center.

In contrast to short time polymerizations $(0.5-2 \mathrm{~min}$, cf. Table 1), in which nearly complete absence of chain transfer was evident, the number of chain transfers increases in $60 \mathrm{~min}$ polymerizations at $15{ }^{\circ} \mathrm{C}, 10-40$ bar ethylene, SDS $/ \mathrm{H}_{2} \mathrm{O}$ and reaches ca. 2 chain transfers per nickel based on polymer yield and GPC polymer molecular weight in combination with ${ }^{1} \mathrm{H}$ NMR spectra (Table S3). These moderate numbers of chain transfer before catalyst deactivation triggered further polymerization experiments in which $\mathrm{H}_{2} \mathrm{O}$ was replaced by $\mathrm{D}_{2} \mathrm{O}$ in order to distinguish a deuterolysis according to Scheme 4, line 1 , from a bimolecular reductive coupling according to Scheme 4 , line 2 or 3 .

In these polymerizations deuterium-labeled $\mathrm{DH}_{2} \mathrm{C}$ end groups could not be detected in the formed polymer (30 min, 40 bar ethylene) by NMR spectroscopy (Table S4, entry S4-8; also cf. Table S5). In addition, polymerization in $\mathrm{D}_{2} \mathrm{O}$ proceeds slower than in $\mathrm{H}_{2} \mathrm{O}$. More importantly, however, catalyst activity in $\mathrm{D}_{2} \mathrm{O}$ was retained for more than $24 \mathrm{~h}$ (Table S5, entry S5-10, and Figure S26) while complete deactivation was evident under identical reaction conditions within ca. 60 min in $\mathrm{H}_{2} \mathrm{O}$ (Figure 5).

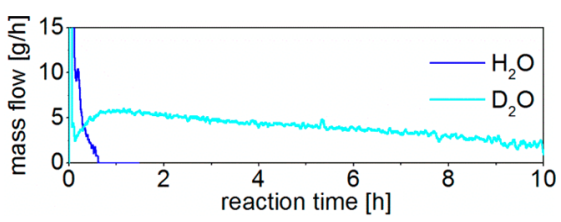

Figure 5. Ethylene consumption during polymerization in water and deuterium oxide, respectively, using catalyst precursor 1-TPPTS.

The molecular weight distributions (MWD) of the products obtained in $\mathrm{D}_{2} \mathrm{O}$ are very narrow for such a reaction, with $M_{\mathrm{w}} /$ $M_{\mathrm{n}}=1.3$ and $M_{\mathrm{n}}=5 \times 10^{5} \mathrm{~g} \mathrm{~mol}^{-1}$ after $24 \mathrm{~h}$. Thus, it is reasonable to assume that the absence of the deuterated chain ends as observed by NMR (vide supra) is due to the simple fact that after $24 \mathrm{~h}$, very little chain deactivation occurred and the vast majority of active centers were still attached to polymer chains prior to precipitating the polymer in methanol during work-up. We suggest that the large increase in catalyst stability is primarily not related to deuterium oxide solvent effects. The dielectric constants of water ${ }^{25}$ and deuterium oxide ${ }^{26}$ are similar, and though the dissolution of ionic compounds is less favored in deuterium oxide than in water, the micelles formed by SDS were described to be similar in size, intermicellar interactions, and headgroup repulsion. ${ }^{27}$ Rather, a pronounced deuterium isotope effect resulting in stronger $\mathrm{O}-\mathrm{D}$ than $\mathrm{O}-\mathrm{H}$ bonds which also has a direct impact on the autodissociation of $\mathrm{D}_{2} \mathrm{O}$ and $\mathrm{H}_{2} \mathrm{O}$ seems responsible for an increased catalyst lifetime in $\mathrm{D}_{2} \mathrm{O}$ when compared to $\mathrm{H}_{2} \mathrm{O}$. More specifically, the autodissociation of $\mathrm{D}_{2} \mathrm{O}\left(\mathrm{pK}_{\mathrm{D}_{2} \mathrm{O}}=-\log \left(\left[\mathrm{DO}^{-}\right]\left[\mathrm{D}_{3} \mathrm{O}^{+}\right]\right)=\right.$ 14.955 and $\mathrm{H}_{2} \mathrm{O}\left(\mathrm{pK}_{\mathrm{H}_{2} \mathrm{O}}=-\log \left(\left[\mathrm{HO}^{-}\right]\left[\mathrm{H}_{3} \mathrm{O}^{+}\right]\right)=14.000\right.$ at $\left.25^{\circ} \mathrm{C}\right)^{28,29}$ suggests that either the anion $\left(\mathrm{DO}^{-}\right.$vs $\left.\mathrm{HO}^{-}\right)$or the cation $\left(\mathrm{D}_{3} \mathrm{O}^{+}\right.$vs $\left.\mathrm{H}_{3} \mathrm{O}^{+}\right)$may be responsible for promoting catalyst deactivation.

In order to investigate which species from $2 \mathrm{H}_{2} \mathrm{O} \leftrightarrows \mathrm{H}_{3} \mathrm{O}^{+}+$ $\mathrm{OH}^{-}$plays the major role in catalyst deactivation, the $\mathrm{pH}$ of the reaction mixture was varied using strong alkali hydroxides or sulfuric acid (for details cf. Table S6). The productivity of the catalyst strongly depends on the $\mathrm{pH}$ of the reaction mixture (Figure 6, Figure S27 and Table S6). Under acidic conditions, the catalyst is rapidly deactivated, and only traces of polymer could be obtained even at $\mathrm{pH}$ 6.7. On the other hand, under basic conditions the catalyst productivity increases with $\mathrm{pH}$ and at $\mathrm{pH} 12.5$ polyethylene with a very narrow molecular weight distribution of $M_{\mathrm{w}} / M_{\mathrm{n}}=1.2$ at $M_{\mathrm{n}}=7 \times 10^{5} \mathrm{~g} \mathrm{~mol}^{-1}$ could be obtained after $60 \mathrm{~min}$ of polymerization (cf. Table S6). We suggest that catalyst deactivation in catalytic aqueous polymerization of ethylene occurs via a protonolysis reaction (Scheme 4 , line 1), as indicated by the observed strong deactivation of the catalyst by acids. This is in accordance with the significantly longer activity of the catalyst in deuterium oxide which has a lower $\left[\mathrm{D}_{3} \mathrm{O}^{+}\right]$at neutral point due to the lower autodissociation of deuterium oxide. Additionally, deuterium forms stronger $\sigma$ bonds compared to hydrogen; thus, reactions which require a breaking of such bonds (like protonolysis reactions) are disfavored. Note that in deuterium oxide no difference in catalyst activity between the polymerization at neutral point and at $\mathrm{pD} 10$ was observed.

Concerning their microstructure, the polymers obtained at $\mathrm{pH} 12.5$ are highly linear with $<1$ branch/1000 carbon atoms. The crystallinity of the precipitated polymer is $>90 \%$ according to DSC. The narrow molecular weight distribution $\left(M_{\mathrm{w}} / M_{\mathrm{n}}=\right.$ 1.2 at $M_{\mathrm{n}}=7 \times 10^{5} \mathrm{~g} \mathrm{~mol}^{-1}$, vide supra) in combination with the low branching density indicates polymer chain growth conditions nearly undisturbed by competing (irreversible) chain termination, chain transfer reactions, or chain walking. Consequently, polymer particle growth is also mostly unaffected by transfer and termination reactions as well as by chain walking under these polymerization conditions.

Suppressed Catalyst Deactivation by Additives. We also identified weakly coordinating compounds which can improve the stability of the catalyst. These ligands are usually (weakly) basic amides or tertiary amines (cf. Table S7-S10, Figures S32 and S34). For example, using $1.3 \mathrm{~mol} \mathrm{~L}^{-1} \mathrm{DMF}$,
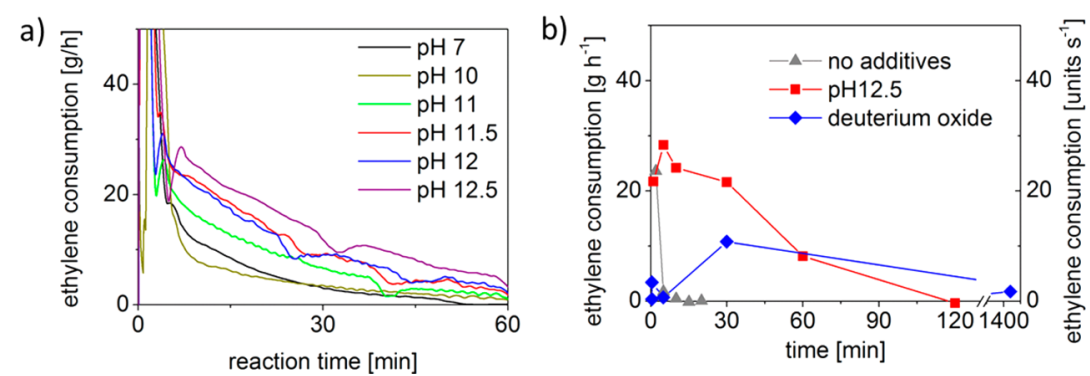

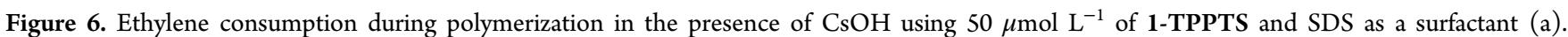
Ethylene consumption $\mathrm{d}$ (ethylene)/dt estimated from polyethylene yields in sampling experiments (b). 
the catalyst remains stable for more than $10 \mathrm{~h}$. Here, a clear correlation of DMF concentration and catalyst stability could be shown (cf. Table S7). The more weakly coordinating compound is added, the more stable over time the catalyst becomes, however, at the expense of the polymerization rate. These findings are strong indications that DMF coordinates weakly and reversibly to the active center. The competitive coordination of DMF and ethylene slows down the polymerization, and this effect is more pronounced at higher DMF concentrations. We also studied a range of other potentially coordinating compounds (cf. Table S8) with the outcome that similar effects to those observed in the case of DMF can be obtained using weakly coordinating, (weakly) basic, tertiary amines, while addition of (weakly) coordinating, (weakly) acidic compounds always results in catalyst deactivation (cf. Tables S8-S10).

Because of the particularly strong dependence of catalyst productivity on the $\mathrm{pH}$ and its remarkable stability in $\mathrm{D}_{2} \mathrm{O}$, we believe that the main catalyst decomposition mechanism under pressure reactor conditions is hydrolysis (or rather protonolysis) of the active species, resulting in elimination of the saturated polyethylene chain (Scheme 2 and Scheme 4, line 1).

Polymerization Rates. Considering the polymerization rate in aqueous ethylene polymerization using 1-TPPTS, it is reasonable to distinguish two cases. The average polymerization rate describes how much polymer was produced on average per time unit from activation until the total deactivation of the catalyst. The initial polymerization rate of an active center is of interest, when the molecular reaction rates are considered and the maximum catalyst productivity is to be estimated. The latter is particularly difficult to access when polymerization reactions are strongly influenced by deactivation reactions. Even so, for most catalytic polymerization reactions with rapid activation the initial polymerization rate should be approximately equal to the polymerization rate during the first minutes of polymerization.

A previously reported polymerization rate of $\sim 10$ ethylene units $\mathrm{s}^{-1} \times \mathrm{Ni}^{1-}$ for a water-soluble TPPTS-substituted catalyst precursor with similar structure to 1-TPPTS was an average polymerization rate which was calculated from the overall polymer yield. ${ }^{30}$ In the case of the ethylene polymerization using 1-TPPTS at $\mathrm{pH} 7$ average polymerization rates of 5 units $\mathrm{s}^{-1}$ are observed after a reaction time of $30 \mathrm{~min} .{ }^{12}$ In the case of ethylene polymerization using 1-TPPTS at $\mathrm{pH} 12.5$ the average polymerization rate is higher, being 14 units $\mathrm{s}^{-1}$. However, knowing that the catalyst deactivation is strongly affected by the $\mathrm{pH}$ of the aqueous solution, it is useful to determine polymerization rates at the initial stage of the polymerization (Figure 6b). In neutral or basic environments, initial polymerization rates (estimated from polymer yields after the first 2 min of polymerization) are very similar, being $\sim 25$ units $\mathrm{s}^{-1}$. That is, the actual productivity of the catalytically active center is independent of the $\mathrm{pH}$ of the reaction. The main difference between the polymerization at $\mathrm{pH} 7$ and $\mathrm{pH} 12.5$ is that in the latter case the active centers remain active for a longer period of time, and therefore on a longer time scale these active centers can produce more polymer than is the case at $\mathrm{pH} 7$.

As outlined above, in systems in which the catalyst is stabilized by weakly coordinating ligand like DMF the polymerization rate depends on the concentration of the added ligand. For example, at $0.65 \mathrm{~mol} \mathrm{~L}^{-1} \mathrm{DMF}$ initial polymerization rates of $\sim 1$ unit $\mathrm{s}^{-1}$ are observed vs 8 units $\mathrm{s}^{-1}$ at $0.13 \mathrm{~mol} \mathrm{~L}^{-1} \mathrm{DMF}$ (for details cf. Table S7). We suggest that this is the result of competitive coordination between DMF and ethylene; that is, at higher DMF concentrations more "dormant" DMF-coordinated nickel species and less active ethylene-coordinated species are present.

In the case of $\mathrm{D}_{2} \mathrm{O}$ initial polymerization rate of $\sim 5$ units ethylene $\mathrm{s}^{-1}$ are observed. The average polymerization rates which were calculated from ethylene consumption according to

$$
u\left[\text { units s}^{-1}\right]=\frac{\text { ethylene consumption }\left[\frac{\mathrm{g}}{\mathrm{s}}\right]}{28\left[\frac{\mathrm{g}}{\mathrm{mol}}\right] n_{\text {catalyst precursor }}[\mathrm{mol}]}
$$

using mass flow data e.g. from Figure 5 are similar, being 2-5 units ethylene $\mathrm{s}^{-1}$. The catalyst deactivation is suppressed in $\mathrm{D}_{2} \mathrm{O}$, and the polymer is produced at almost constant rate over an extended period of time which can also be seen from the similar initial and average polymerization rate. The reason for the reduced polymerization rate in $\mathrm{D}_{2} \mathrm{O}$ compared to $\mathrm{H}_{2} \mathrm{O}$ remains unclear.

Formation and Growth of Polyethylene Nanocrystals. Using 1-TPPTS under standard polymerization conditions and $\mathrm{pH} \mathrm{7,} \mathrm{stable} \mathrm{dispersions} \mathrm{containing} 6 \mathrm{~nm}$ single-lamella hexagons (particle size according to DLS) of semicrystalline polyethylene ( $>65 \%$ crystallinity according to DSC analysis of the sample after work-up) with a molecular weight of $\sim 1 \times 10^{4}$ $\mathrm{g} \mathrm{mol}^{-1}$ can be obtained after $30 \mathrm{~s}$ of polymerization $(30 \mathrm{~s}$ polymerization after the constant pressure of 40 bar was reached inside the reactor). In contrast, polyethylene which was obtained after $10 \mathrm{~min}$ of polymerization under otherwise identical conditions has a molecular weight of $\sim 1 \times 10^{5} \mathrm{~g}$ $\mathrm{mol}^{-1}$.

These results suggest that the catalyst formed from 1-TPPTS polymerizes ethylene efficiently, as indicated by the rapid increase of the molecular weight of the polymer chains. These steadily growing chains are highly hydrophobic and rapidly arrange into small crystals; thus, highly crystalline polyethylene particles are generated in the very first seconds of the polymerization already. However, the evolution of the particle size and shape during the course of the polymerization remains unclear so far. Therefore, a time-dependent sampling during the polymerization enabling a concise analysis of particle size and shape during one progressing polymerization was sought. To enable such studies, which require drawing samples from an aqueous emulsion/dispersion at $40 \mathrm{bar}$, a customized pressurizable automated sampling chamber was connected to the bottom of the autoclave reactor enabling drawing of up to six samples from the same reaction mixture at intervals as low as $30 \mathrm{~s}$ (detailed description of the sampling experiments; the sampling chamber and the sampling procedure can be found in the Supporting Information, pp S41-S48). Two sets of polymerization conditions, the standard aqueous ethylene polymerization at $\mathrm{pH} \mathrm{7}$, i.e., without addition of Brønstedt base or acid, and aqueous polymerization in the presence of $0.13 \mathrm{~mol} \mathrm{~L}^{-1} \mathrm{DMF}$, were studied. SDS was used as a surfactant to stabilize the emulsion/dispersion at an initial [SDS] of 13$260 \mathrm{mmol} \mathrm{L}^{-1}(0.4-7 \mathrm{wt} \%)$, and polymerizations were conducted for the desired time at $15{ }^{\circ} \mathrm{C}, 40$ bar ethylene pressure.

Concerning the role of the surfactant during the particle formation and growth in both sets of polymerization conditions, an increase of the polymer content goes along with an observable increase of the surface tension of the dispersion which indicates adsorption of the surfactant onto the particle surface. A uniform particle growth is strongly correlated 

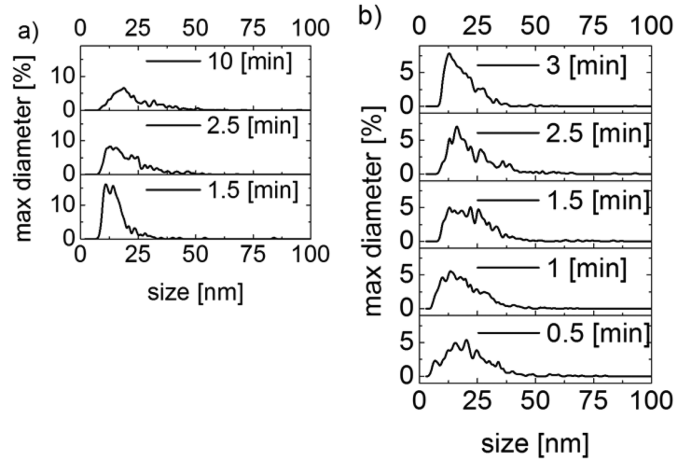

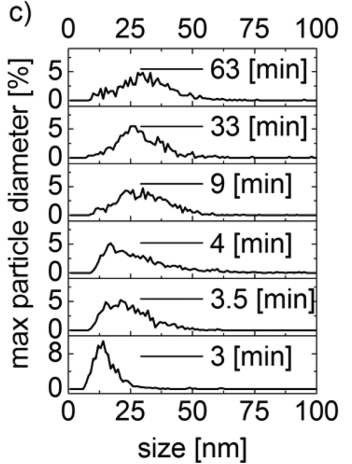

Figure 7. Maximum particle size distribution estimated by TEM. Samples were obtained (a) without DMF and (b, c) with 0.13 mol $\mathrm{L}^{-1} \mathrm{DMF}$. Reaction time does not include the time required for pressurization of the reaction mixture to 40 bar.

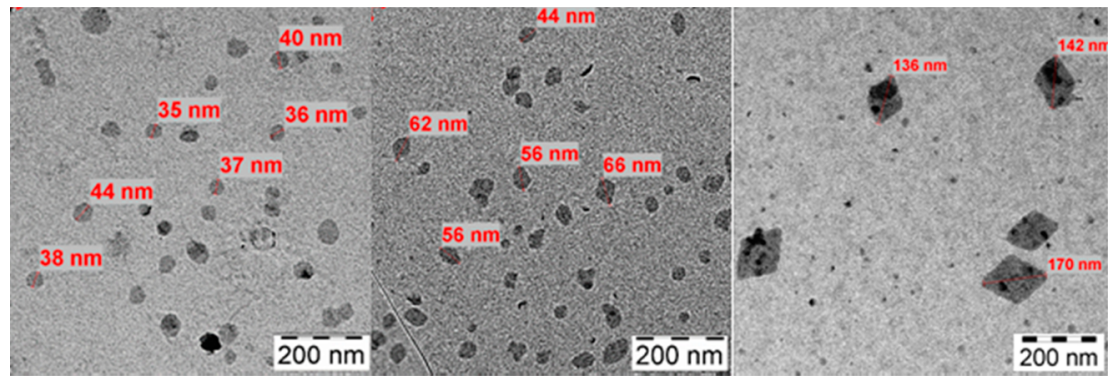

Figure 8. Development of particle shapes from predominantly hexagonal platelets (left) through truncated lozenges (middle) to predominantly lozenges (right) with increasing particle size.

to the surface tension of the reaction mixture as bimodal particle size distributions containing very large $(>100 \mathrm{~nm})$, and small particles are observed whenever the surface tension exceeds $\gamma>65 \mathrm{mN} \mathrm{m}^{-1}$ during the polymerization (e.g., Figure S56).

Under low surface tension conditions $\left(\gamma<65 \mathrm{mN} \mathrm{m}^{-1}\right)$ the evolution of the particle diameters in dispersions obtained from sampling experiments was analyzed via TEM imaging: 5001000 particles of a micrograph were counted, and regardless of their orientation on the TEM grid the maximum diameter of the (anisotropic platelet-like) particles were taken as a measure of their size (for details cf. Supporting Information, Figures S42, S44, S48, S49 and Tables S13-S15). This analysis (Figure 7a) reveals that the particles form as monolamellar structures and that the average maximum particle diameter $d$ (with $d=2 r$ from Figure 2) increases with time in aqueous ethylene polymerization using 1-TPPTS at standard reaction conditions. The increase of the particle size goes along with the broadening of the particle size distribution (PSD). Such observations are in accordance with scenarios in which either some particles cease to grow (e.g., due to catalyst deactivation or chain transfer) or new particles are formed (e.g., after chain transfer or due to ongoing initiation).

In order to suppress catalyst deactivation and follow the particle growth over longer periods of time, polymerizations in the presence of DMF were therefore studied. In this case, the catalyst is active for almost $2 \mathrm{~h}$, and only a minor decay of the ethylene consumption is observed during the first hour of polymerization (cf. Figure S32). In the first $3 \mathrm{~min}$ small particles are observed (Figure $7 \mathrm{~b}$ ), and after about 4 min the PSD starts to broaden and gets shifted to larger particle sizes (Figure 7c). After $63 \mathrm{~min}$, the majority of the particles are much larger (average diameter ca. $30 \mathrm{~nm}$ ) than the particles observed after $3 \mathrm{~min}$ of polymerization (average diameter ca. $14 \mathrm{~nm}$ ). We will discuss later that under essentially all polymerization conditions (not just at $\mathrm{pH}=7$ and in the presence or absence of DMF; vide infra) the number of chains per particle is close to 1 and that increasing molecular weight results in increasing particle sizes. These data indicate that individual particles irrespective of a potential chain transfer are grown by one catalytically active nickel center. Considering the short time polymerization experiments in the absence of DMF, this also implies that particle growth stops once the catalytically active nickel center is deactivated. Another important implication of the evolution of particle sizes over time is that by virtue of the decreasing number of very small particles over time the formation of (new) particles is essentially restricted to the initiation phase of the polymerization; i.e., the number of particles roughly corresponds to the number of active nickel centers, and there is essentially no chain transfer by which new particles form.

The analyzed particles are typically single-lamella hexagons and, with increasing size, truncated lozenges as long as they are $<$ ca. $100 \mathrm{~nm}$ in diameter; for particles diameters >ca. $100 \mathrm{~nm}$ they are mostly lozenge-shaped (Figure 8).

Generally, in polyethylene samples having a molecular weight of $M_{n}=(5-7) \times 10^{5} \mathrm{~g} \mathrm{~mol}^{-1}$ the majority of the particles were shaped as truncated lozenges or lozenges (Figure S53). For larger lozenges a "folded" structure is observed across the center of such $8 \mathrm{~nm}$ thin lamellae (cf. Figure S55). We suggest that large lamellae were formed as three-dimensional hollow pyramids, rather than flat lozenges and the deformation in the center of the lamella upon drying of a hollow pyramid-like particle on a flat substrate results in a collapse of the hollow top. Hollow pyramids have been described as typical structures of unsupported micrometer-sized polyethylene crystals grown from dilute solution at high temperature. ${ }^{31,32}$ It should be noted that independent of particle size, all particles studied here, also 
the large ones, are single crystals and show clear diffraction patterns corresponding to the orthorhombic PE crystal lattice (Figure 9).

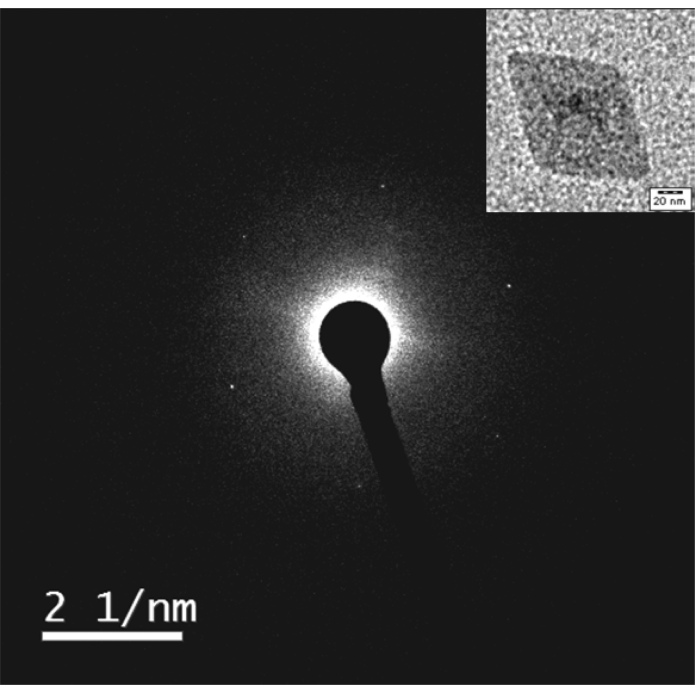

Figure $9.8 \mathrm{~nm}$ thin lozenge-shaped particle and its diffraction pattern. ED pattern corresponds to a polyethylene single crystal.

Another interesting observation is that particles which were obtained after $30 \mathrm{~s}$ in aqueous ethylene polymerization at $\mathrm{pH}=$ 7 have thicknesses of $4.1 \pm 0.6 \mathrm{~nm}$. After $1.5 \mathrm{~min}$ the particle thickness apparently increases to $4.5 \pm 0.7 \mathrm{~nm}$, and after 10 min polymerization particles with a thickness of $7.1 \pm 0.8 \mathrm{~nm}$ are observed. No further evolution of the particle thickness was observed in samples obtained after longer polymerization time for all reaction conditions studied (in the presence of coordinating ligands, at higher $\mathrm{pH}$ or in $\mathrm{D}_{2} \mathrm{O}$, e.g., Figures S52 and S54). The particle thicknesses of the polyethylene nanocrystals were obtained by AFM or by TEM from the measurement of the smallest dimension of $\sim 20$ particles which are oriented perpendicularly to the grid (indicated by high electron density) (for details cf. Figures S45 and S54). The particle thickness of larger particles was also estimated from electron energy loss via TEM assuming that the particle consists of pure carbon (Figure S52).

The thickening of the polyethylene nanocrystals with polymerization/particle growth time deserves further special comments:

(a) The formation of micrometer-sized polyethylene or longalkane crystals from melt or from diluted solution has been studied extensively. It is known that up to a certain chain length linear alkanes crystallize as extended chains, and the lamellar thickness $L_{\mathrm{c}}$ of the crystals is determined by the length of the chain. ${ }^{33-35}$ Longer alkanes show a tendency to crystallize as once folded or twice folded chains, depending on the undercooling present during crystallization. ${ }^{35,36}$ Analogously to the long-chain alkanes, linear polyethylenes crystallize as ntimes folded chains. ${ }^{33,37}$ Here also the actual lamella thickness, and therefore the number of foldings, mostly depend on the crystal formation temperature, and at stronger undercooling lower lamella thicknesses are obtained according to the GibbsThomson equation $T_{\mathrm{c}}=T_{\mathrm{c}}^{\infty}\left(1-\alpha / L_{\mathrm{c}}\right)$, with $\alpha=2 \sigma / \Delta H$, where $\Delta H=$ heat of fusion, $\sigma=$ surface free energy of the lamellae, and $T^{\infty}=$ the temperature limit referring to fully crystalline samples. ${ }^{17,33,34,38,39}$

(b) Previously it was reported that the lamellar thickness expected for the nascent polyethylene crystals obtained at 15 ${ }^{\circ} \mathrm{C}$ with 1-TPPTS according to $T=T^{\infty}\left(1-\alpha L_{\mathrm{c}}\right)$ is lower than the experimentally observed lamellar thickness of $6.3 \pm 0.8 \mathrm{~nm}$ obtained after $30 \mathrm{~min}$ polymerization. The deviation of experimentally found and theoretically expected lamellar thickness was explained by postcrystallization reorganization or lamellar thickening. ${ }^{17}$

Thus, the increase in lamellar thickness from 4.1 (30 s) to 4.5 $(1.5 \mathrm{~min})$ to $7.1 \mathrm{~nm}(10 \mathrm{~min})$ observed in this study with increasing polymerization time provides evidence that a mechanism of postcrystallization reorganization or lamellar thickening is indeed operative and occurs immediately during the ongoing polymerization.

Correlation of Particle Size and Molecular Weight. In order to elucidate the influence of polymer chain growth on the growth of polymer particles, molecular weights of the polyethylenes obtained at different conditions were plotted against the hydrodynamic DLS radius $D_{\mathrm{h}}$ of the polymer particles (Figure 10). We further calculated the theoretical size
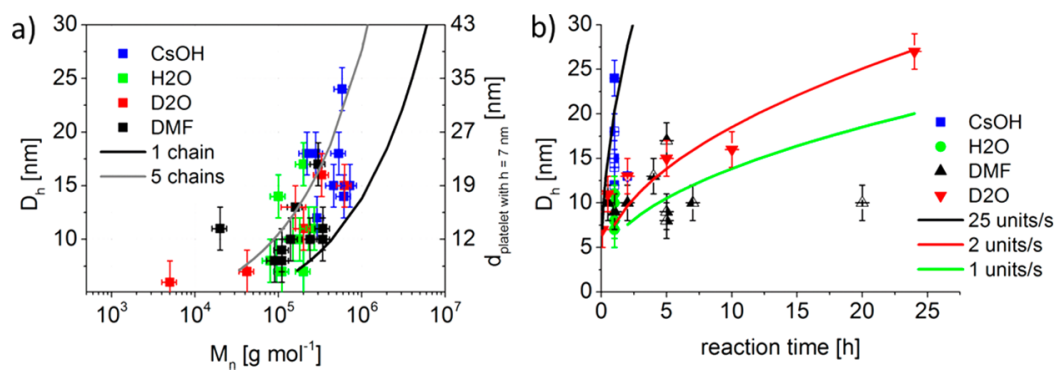

Figure 10. (a) Particle diameter vs the molecular weight of the polyethylene. Dispersions obtained at different reaction conditions: $\mathrm{pH} 7\left(\mathrm{H}_{2} \mathrm{O}\right), \mathrm{pH}$ 9-12.5 ( $\mathrm{CsOH})$; in aqueous solution in the presence of DMF (DMF); in deuterium oxide $\left(\mathrm{D}_{2} \mathrm{O}\right)$. The molecular weights obtained by GPC, the hydrodynamic radius $D_{\mathrm{h}}$ obtained by DLS measurement assuming spherical particles (number weighted particle size distribution). Theoretical particle diameters $d$ were calculated according to eq 2 assuming a constant particle thickness of $7 \mathrm{~nm}$ and single-chain particles (black curve) or particles consisting of 5 chains (gray curve). The hydrodynamic radius $D_{\mathrm{h}}$ of the platelet does not correspond to its physical radius $d$. $D_{\mathrm{h}}$ of a platelet with a diameter $d$ and a thickness $h=7$ can be calculated using an approximation for an oblate ellipsoid, eq S10 from the Supporting Information. In Figure 10 the $d_{\text {platelet with } h=7 \mathrm{~nm}}$ axis and $D_{\mathrm{h}}$ axis relate to each other according to this equation. (b) Hydrodynamic particle diameter $D_{\mathrm{h}}$ obtained by DLS and theoretically expected diameter $D_{\mathrm{h}}$ of a single-chain particle assuming particle growth rate $u$ of 25 units s$^{-1}$ (black), 2 units s-1 (red), and 1 units $\mathrm{s}^{-1}$ (green). Particle diameters $D_{\mathrm{h}}$ calculated according to eqs 2 and 3 as well as eq S10. Symbols with different filling grade correspond to experiments where different concentrations of the additive were used. Data from Table S3 and Tables S5-S7. 
of a polymer particle consisting of $X$ polyethylene chains with molecular weight $M_{\mathrm{n}}$ and particle thickness $h$, crystallized in an orthorhombic polyethylene cell with cell parameters $a=7.42 \AA$, $b=4.95 \AA, c=2.55 \AA{ }^{40}$ number of ethylene units per cell $N_{\text {unit }}$ $=2$, and tightly folded chains, according to

$$
d=\sqrt{\frac{a b c X \frac{M_{\mathrm{n}}}{28 \mathrm{~g} / \mathrm{mol} \cdot N_{\mathrm{unit}}}}{h \pi}}
$$

Figure 10 displays the calculated $d$ for a particle with $X=1$ chain or $X=5$ chains. Note, here, the calculated particle diameter corresponds to the physical diameter $d$ of a thin round platelet and differs from the hydrodynamic diameter $D_{\mathrm{h}}$ of such a platelet. $D_{\mathrm{h}}$ of a thin platelet can be calculated according to eq S10 of the Supporting Information using an approximation of an oblate ellipsoid. In Figure 10 the diameter $d$ of a platelet with a thickness $h=7 \mathrm{~nm}$ is shown using the right $y$-axis, and the prediction of the equivalent $D_{\mathrm{h}}$ of the same particle can be seen on the left $y$-axis.

According to Figure 10, for the majority of the samples studied the particle size correlates with the molecular weight and typically, larger particles have higher molecular weights. Comparing the experimental particle sizes and the particle sizes expected according to our calculation, the number of polymer chains per particle is close to unity (under all experimental conditions studied, with the exception of polymerization without surfactant or involving surface tensions exceeding $\gamma>$ $65 \mathrm{mN} \mathrm{m}^{-1}$ during the polymerization, which results in the formation of abnormally large (>200 nm lozenge shaped particles)).

Assuming that the majority of the particles are single-chain particles, the expected polymerization rates can be estimated using the approximations from eq 2 and eq S10 and assuming that

$$
M_{\mathrm{n}}=(28 \mathrm{~g} / \mathrm{mol})\left(u\left[\text { units s }^{-1}\right] \cdot t[\mathrm{~s}]\right)
$$

Note that in this equation the deactivation of the catalyst is completely neglected; thus, this approximation is only applicable to systems with little catalyst deactivation (e.g., at high $\mathrm{pH}$ or in the presence of weakly coordinating ligands). For the polymerization at high $\mathrm{pH}$, high polymerization rates of $\sim 25$ units $\mathrm{s}^{-1}$ best fit experimental and calculated crystal sizes (cf. experimental points "CsOH" vs black curve, Figure 10b). In the presence of DMF the particles grow slower, and the polymerization rates vary, depending on the concentration of DMF (cf. experimental points "DMF"). In the case of polymerization in deuterated water, according to the particle size analysis, we would expect polymerization rates of $\sim 2$ units $\mathrm{s}^{-1}$ (cf. experimental points " $\mathrm{D}_{2} \mathrm{O}$ " and the red curve, Figure 10b). In general, the initial polymerization rates which were calculated using the polymer yield (as discussed in the Polymerization Rates section) correspond to the polymerization rates which are necessary for the formation of particles with a DLS hydrodynamic diameter $D_{\mathrm{h}}$. Thus, the observed particle diameters and the estimation of the single chain-particle diameters which would be obtained when polymer chains grow with a constant growing rate $u$ do not contradict the assumption of a single-chain-particle. According to eqs 2 and 3 , we can expect that the physical diameter $d$ of a thin round single-chain platelet with a constant thickness $h$ grows according to $d \sim \sqrt{ } t$, when the ethylene polymerization rate $u$ is constant and the activation of the catalyst occurs immediately.
We compared particle numbers $N_{\text {part }}$ and the number of nickel precursor molecules which were added at the beginning of the reaction $N_{\text {cat, }}$ assuming that $N_{\text {part }}=V_{\text {total }} / V_{\text {part,mean. }}{ }^{4}$ When the reaction was run until total deactivation, we observe that $N_{\text {cat }} \approx N_{\text {part }}$ meaning that per Ni center about one particle was generated (cf. Figure 11). Alternatively, looking at short-

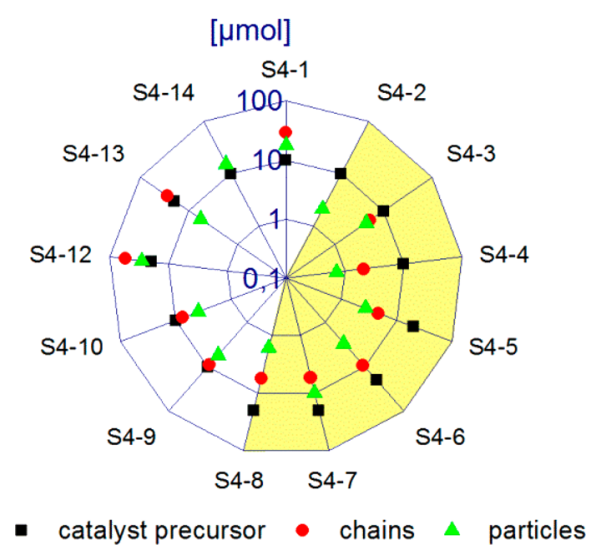

Figure 11. Comparison of the particle numbers $N_{\text {part }}$ the chain numbers, and the amount of the catalyst precursor $N_{\text {cat }}$ applied in aqueous catalytic polymerization in short- or long-term experiments (from Table S4). Short-term experiments (30 s-2 min) are highlighted in yellow.

time experiments, where the reaction was quenched after a few minutes of polymerization, $N_{\text {cat }} \approx 10 N_{\text {part }}$ which implies that $\sim 10 \%$ of the catalyst precursor is initiated directly after ethylene addition (cf. yellow-highlighted region of Figure 11, reaction conditions for the generation of the analyzed samples are displayed in Table S4). This agrees well with the portion of the activated catalyst precursor calculated from the number of the ${ }^{13} \mathrm{C}$-labeled chain ends which were generated under true pressure reactor conditions using catalyst precursor $1-{ }^{13} \mathrm{C}$ TPPTS, i.e., ca. $20 \%$ initiated precursor after $30 \mathrm{~s}$, ca. $45 \%$ after 2 min (vide supra).

We also compared the particle numbers $N_{\text {part }}$ with the chain numbers $N_{\text {chain }}$ generated in this system. The number of chains was calculated according to $N_{\text {chain }}=m_{\text {total,polymer }} / M_{\mathrm{n}}$. We observe, in most cases $N_{\text {chain }} \approx N_{\text {part }}$, independent of polymerization time or reaction conditions (cf. Figure 11). Thus, on the basis of the above observations, we suggest that $N_{\text {chain }} \approx N_{\text {part }} \approx N_{\text {cat }}$ meaning that the majority of particles consists of one chain which was generated by one nickel center.

This conclusion has far-reaching implications: it suggests that the molecular weight and the size of a particle are only governed by the catalyst lifetime and that the aqueous ethylene polymerization is a potentially living reaction. With sufficiently stable catalysts, polyethylene particles, each consisting of one polymer chain of high molecular weight, can be generated quantitatively using the water-soluble catalyst precursor 1TPPTS. Examples of such polymerization systems (polymerization in the presence of DMF or at high $\mathrm{pH}$, or deuterium oxide as reaction medium, etc.) were presented as a part of this study.

\section{CONCLUSION}

Aqueous polyethylene nanocrystal dispersions are a unique and versatile system with a high potential for the development of new materials. They contain linear high molecular weight 
Scheme 5. Particle Formation Mechanism in Aqueous Catalytic Ethylene Polymerization

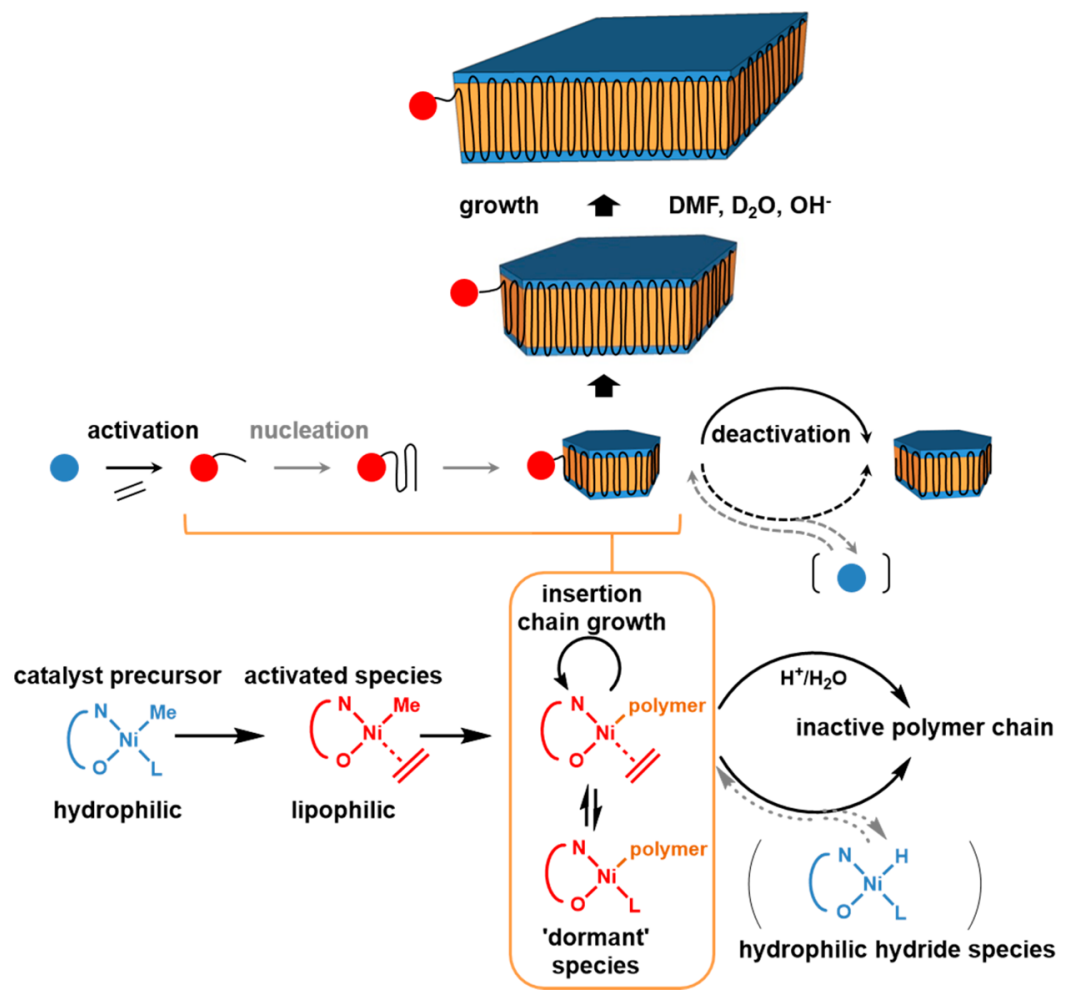

polyethylene in the unusual form of nonaggregated and very small single crystals. This compartmented nature results in a low degree of entanglement. An orderly deposition of the chain during polymerization can result in ideal crystals with a high degree of order. ${ }^{30}$ In a more general sense, the unusually high degree of dispersion represented by such nanoparticles can be used for the generation of intimately mixed composites with other materials.

The mechanisms of the particle formation in a multiphase system, as present in our case, are unusual and instructive as the polymeric phase is generated directly from an initial homogeneous aqueous catalyst solution. The findings reported give first and fundamental insights into the formation of nanocrystal dispersions.

The formation of the aqueous polymer dispersion by the catalytic path can be described as the interplay of (a) the polymerization mechanism on the molecular scale, including the catalyst activation and catalyst deactivation mechanisms, (b) the particle nucleation and growth interrelated with the formation of a new solid phase, and (c) the consideration of the chemical and physical equilibria present between those phases (Scheme 5).

When added to the aqueous surfactant solution and charged with ethylene the applied catalyst precursor $\left[\kappa^{2}-N, O-\{2,6\right.$ $\left.\left(3^{\prime}, 5^{\prime}-\left(\mathrm{F}_{3} \mathrm{C}\right)_{2} \mathrm{C}_{6} \mathrm{H}_{3}\right)_{2} \mathrm{C}_{6} \mathrm{H}_{3}-\mathrm{N}=\mathrm{C}(\mathrm{H})-\left(3,5-\mathrm{I}_{2}-2-\mathrm{O}-\mathrm{C}_{6} \mathrm{H}_{2}\right)\right\}-$ $\left.\mathrm{NiCH}_{3}\left\{\mathrm{P}\left(3-\mathrm{C}_{6} \mathrm{H}_{4} \mathrm{SO}_{3} \mathrm{Na}\right)_{3}\right\}\right]$ (1-TPPTS) is rapidly transformed into an (lipophilic) active species by dissociation of the TPPTS ligand and by coordination of ethylene to the free coordination site. We accessed the activation of the catalyst precursor using labeled $1-{ }^{13}$ C-TPPTS catalyst precursor under true pressure reactor conditions. These studies show that already in the early stages of the polymerization a substantial part of the catalyst precursor (after $30 \mathrm{~s}$ : $20-28 \%$; after $2 \mathrm{~min}$ : ca. $45 \%)$ has been activated. These results are also confirmed in short-term experiments by comparison of chain numbers, accessed from polymer yields using the polymer's molecular weight, and particle numbers generated per nickel center, accessed from polymer yields and the average particle size. Here, each particle consists of $\sim 1$ polymer chain, but only 1 particle is generated per 10 catalyst precursor molecules applied (corresponding to $\sim 10 \%$ initiation). Calculations of the particle and chain numbers of samples obtained after longer polymerization times $(>10 \mathrm{~min}$ ) show that approximately one single chain particle is formed per nickel center, meaning that in the first minutes of the reaction the major part of the catalyst precursor is activated.

When performed in aqueous surfactant solution at $15{ }^{\circ} \mathrm{C}, 40$ bar, and $\mathrm{pH} 7$, the ethylene polymerization ceases completely within a short period of time $(\sim 30 \mathrm{~min})$. As concluded from the rapid uptake of the ethylene consumption, the deactivation reactions start directly after addition of ethylene. On the molecular scale, the deactivation reactions result in the formation of fully saturated polymer chains. By exposing the catalyst precursor to water or surfactant solution prior to polymerization, we demonstrated that the catalyst precursor deactivates in an aqueous environment within $2 \mathrm{~h}$. Under true pressure reactor conditions we could show that deactivation of the active nickel species is related to water or more likely its dissociation products. Substitution of $\mathrm{H}_{2} \mathrm{O}$ by $\mathrm{D}_{2} \mathrm{O}$ as a reaction medium resulted in a virtually living catalyst behavior ((TOF 4000 ethylene (catalyst precursor) ${ }^{-1} \mathrm{~h}^{-1}$ for more than $24 \mathrm{~h}$ and increasing molecular weight). We relate the strong difference in polymerization behavior in these two very similar solvents to the lower degree of dissociation of $\mathrm{D}_{2} \mathrm{O}$ compared to water and comparably stronger $\mathrm{O}-\mathrm{D}$ bonds which would potentially influence the reactivity and coordination strength of $\mathrm{D}_{2} \mathrm{O}$ and its dissociation products. Inspired by these observations, we studied the influence of the $\mathrm{pH}$ on the 
catalyst stability. The catalyst is rapidly deactivated by acids, and already at $\mathrm{pH} 6.7$ only traces of polymer are obtained. On the other hand, at $\mathrm{pH} 12.5,7 \mathrm{wt} \%$ dispersions of high molecular weight polyethylene $\left(M_{\mathrm{n}}=7.2 \times 10^{5} \mathrm{~g} \mathrm{~mol}^{-1}\right)$ are generated within $60 \mathrm{~min}$ vs $1 \mathrm{wt} \%$ polyethylene dispersions $\left(M_{\mathrm{n}}=1.0 \times 10^{5} \mathrm{~g} \mathrm{~mol}^{-1}\right)$ which are obtained at $\mathrm{pH} 7$ under otherwise identical conditions. Consequently, we assume that protonolysis/deuterolysis of nickel-polymeryl species is the predominant catalyst deactivation reaction under aqueous pressure reactor polymerization conditions.

Additionally, we observed that (slightly) basic, weakly coordinating ligands like DMF significantly increase the catalyst lifetime at strongly reduced polymerization rates. In neutral or basic environments, initial polymerization rates (estimated from the first $2 \mathrm{~min}$ of polymerization) are $\sim 25$ units $\mathrm{s}^{-1}$. In the presence of a weakly coordinating ligand, e.g. DMF, polymerization rates depend on the ligand concentration, and at 0.65 mol L ${ }^{-1}$ DMF polymerization rates of $\sim 1$ unit s$^{-1}$ are observed (vs 8 units $\mathrm{s}^{-1}$ at $0.13 \mathrm{~mol} \mathrm{~L}^{-1} \mathrm{DMF}$ ). We suggest that in the presence of DMF the polymerization rate is reduced due to the competitive coordination of ethylene and DMF, and the reduced deactivation of the active center is due to the reversible coordination of latter.

The locus of polymerization is a further fundamental aspect of this multiphase system. Related to this, the question also arises whether the catalyst can pass through the phase boundaries or remains on the surface of the same particle at any time. In sampling experiments we demonstrated that the surfactant is adsorbed on the particle surface, and the addition of the surfactant is a prerequisite for the formation of singlelamella particles. We estimated from particle volumes that approximately one particle is formed per nickel center, and by comparing the particle diameters and the molecular weights of the polymer, we calculated that most particles consist of one polymer chain. Thus, we suggest that in most cases a catalyst precursor species initiates one polymer chain, which nucleates and grows forming a single chain particle. Minor amounts of multichain particles (much larger particles compared to the mean particle size of a sample) are generated in some cases, likely as a result of poorly dispersed catalyst precursor or of fully adsorbed surfactant.

Catalyst deactivation influences the size and the shape of the formed nanocrystals; however, in the presence of stabilizing additives, at high $\mathrm{pH}$ or in $\mathrm{D}_{2} \mathrm{O}$, chain growth and therefore particle growth can be substantially extended. Small hexagonal polyethylene platelets were obtained at initial stages of the polymerization or under conditions of substantial catalyst deactivation. The absence of substantial catalyst deactivation and also of chain transfer in the presence of stabilizing agents or in $\mathrm{D}_{2} \mathrm{O}$ is evidenced by narrow molecular weight distributions, e.g., in aqueous systems in the presence of $1.3 \mathrm{~mol} \mathrm{~L}^{-1} \mathrm{DMF}$ $M_{\mathrm{w}} / M_{\mathrm{n}}=1.5$ and $M_{\mathrm{n}}=3.4 \times 10^{5} \mathrm{~g} \mathrm{~mol}^{-1}$ are obtained vs $M_{\mathrm{w}} /$ $M_{\mathrm{n}}=2.1$ and $M_{\mathrm{n}}=0.9 \times 10^{5} \mathrm{~g} \mathrm{~mol}^{-1}$ in aqueous polymerization without DMF. The most significant catalyst stabilization can be achieved in deuterium oxide as the reaction medium without any additives. Here, after $24 \mathrm{~h}$ polymerization polymers with $M_{\mathrm{w}} / M_{\mathrm{n}}=1.3$ and $M_{\mathrm{n}}=5.1 \times 10^{5} \mathrm{~g} \mathrm{~mol}^{-1}$ are obtained, and the polymerization has a "living" character. In such systems with reduced catalyst deactivation and chain transfer, we also monitored the transformation of the plateletlike, hexagon-shaped native polyethylene nanocrystals into truncated lozenges and finally into much larger lozenges, or more likely hollow pyramids. These data confirm that nascent polyethylene nanocrystals form as hexagonal platelets and evolve into truncated lozenges and finally lozenges - the shape which is also observed for polyethylene nanoparticles formed by crystallization from dilute solution at low undercooling.

Beyond providing insights into the unique mechanism of catalytic formation and growth of polymer nanocrystals, these findings also give directions for advancing productivities and control of particle size and shape.

\section{EXPERIMENTAL SECTION}

General Methods and Materials. All steps involving the $\mathrm{Ni}(\mathrm{II})$ catalyst precursor were carried out under an inert atmosphere. Demineralized water was distilled under a nitrogen atmosphere. Deuterium oxide (Eurisotop) was destilled under a nitrogen atmosphere. N,N-Dimethylformamide (DMF) was distilled from calcium hydride under an argon atmosphere. Tetrahydrofuran (THF), dimethyl sulfoxide (DMSO), dimethylacetamide (DMA), $\mathrm{N}$ formylpyrrolidone, $\mathrm{N}$-formylpiperidine, and $\mathrm{N}$-methylformamide were destilled under an argon atmosphere prior to use. Methylformanilide, 2-chlorodimethylacetamide, methyl formate, 1,4-diazabicyclo[2.2.2]octane (DABCO), and 1,8-diazabicyclo[5.4.0] undec-7-ene (DBU) (Aldrich) were thoroughly degassed by several freeze-pump-thaw cycles. Diglyme was used as received (Aldrich). Sodium dodecyl sulfate (SDS) (Fluka) was degassed prior to use. Ethylene of 4.5 grade was supplied by AirLiquide. Oxide-free TPPTS was purchased from abcr. TPPTS (6\% oxide) and TPPTS oxide were synthesized according to literature methods. ${ }^{42}$ NMR spectra of all TPPTS samples are displayed in the Supporting Information (Figures $\mathrm{S} 1-\mathrm{S} 3$ ). $\left[\kappa^{2}\right.$ $\mathrm{N}, \mathrm{O}-\left\{2,6-\left(3^{\prime}, 5^{\prime}-\left(\mathrm{F}_{3} \mathrm{C}\right)_{2} \mathrm{C}_{6} \mathrm{H}_{3}\right)_{2} \mathrm{C}_{6} \mathrm{H}_{3}-\mathrm{N}=\mathrm{C}(\mathrm{H})-\left(3,5-\mathrm{I}_{2}-2-\mathrm{O}-\mathrm{C}_{6} \mathrm{H}_{2}\right)\right\}-$ $\left.\mathrm{NiCH}_{3}\left\{\mathrm{P}\left(3-\mathrm{C}_{6} \mathrm{H}_{4} \mathrm{SO}_{3} \mathrm{Na}\right)_{3}\right\}\right]$ 1-TPPTS was prepared according to ref 12. The ${ }^{13} \mathrm{C}$-labeled analogue $1-{ }^{13} \mathrm{C}$-TPPTS was synthesized in analogy to ref 12 starting from ${ }^{13} \mathrm{C}$-labeled $\left.\left[(\text { tmeda }) \mathrm{Ni}^{13} \mathrm{CH}_{3}\right)_{2}\right]$.

Differential scanning calorimetry (DSC) was performed on a Netzsch DSC 204 F1 instrument with a heating/cooling rate of $10 \mathrm{~K}$ $\mathrm{min}^{-1}$. Dynamic light scattering (DLS) was performed on a Malvern Nano-ZS ZEN 3600 particle sizer (173 ${ }^{\circ}$ backscattering). The autocorrelation function was analyzed using the Malvern dispersion technology software 3.30 algorithm to obtain number weighted particle size distributions. The conductivity measurement was performed on a Malvern Nano-ZS ZEN 3600 particle sizer. The surface tension was determined via dynamic surface tension measurement with a curved platinum plate on a KRÜSS Process Tensiometer K100. Transmission electron microscopy (TEM) was carried out on a Zeiss Libra 120 EF-TEM instrument. For the TEM analyses samples were dialyzed with demineralized water in a Spectrum Laboratories Spectra/Por Dialysis Membrane 1, MWCO 6-8000. The thickness information on a TEM specimen is derived from measurement of the probability of inelastic scattering of the incident electron beam by specimen thickness $d=\lambda \ln \left(I_{\text {tot }} / I_{\text {zero loss }}\right)$, where $\lambda=$ total mean free pathway for inelastic scattering, $I_{\text {tot }}=$ total area beneath the complete spectrum, and $I_{\text {zero loss }}=$ total area under the zero loss peak. The specimen thickness map was obtained from two acquired images: the elastic and the global bright-field image (without energy filtering). For calculating the specimen thickness in nanometers, the mean free path length in carbon was used. AFM measurements were carried out on JPK NanoWizard III instrument. NMR spectra were recorded on a Bruker Avance 400, a Bruker Avance DRX 600, or a Bruker Avance III 600. High-temperature NMR measurements of polymers were performed in 1,1,2,2-tetrachloroethane- $d_{2}$ at $130{ }^{\circ} \mathrm{C}$. Molecular weights $\left(M_{\mathrm{n}}\right)$ were determined from the integrals of the repeat units vs unsaturated end groups in ${ }^{1} \mathrm{H}$ and ${ }^{13} \mathrm{C}$ NMR spectra. Gel permeation chromatography (GPC) was carried out in 1,2,4trichlorobenzene at $160{ }^{\circ} \mathrm{C}$ at a flow rate of $1 \mathrm{~mL} \mathrm{~min}^{-1}$ on a Polymer Laboratories 220 instrument equipped with Olexis columns with differential refractive index, viscosity, and light scattering $\left(15^{\circ}\right.$ and $\left.90^{\circ}\right)$ detectors. Data reported were determined via linear PE standard calibration $\left(M_{\mathrm{w}}<3 \times 10^{4} \mathrm{~g} \mathrm{~mol}^{-1}\right)$, universal calibration $\left(3 \times 10^{4}<\right.$ $\left.M_{\mathrm{w}}<10^{5} \mathrm{~g} \mathrm{~mol}^{-1}\right)$, and triple detection $\left(M_{\mathrm{w}}>10^{5} \mathrm{~g} \mathrm{~mol}^{-1}\right)$ employing the PL GPC-220 software algorithm. As the instrument 
records light scattering at only two angles, data analysis involves an iteration for the calculation of molecular weights and form factors for each measured interval. The instrument was calibrated with narrow polystyrene and polyethylene standards. AUZ measurements were performed using a XLI (SN: COA95D03) device (Beckman Coulter) with interference optics at $60000 \mathrm{rpm}, 25^{\circ} \mathrm{C}$, using a solvent mixture of 1:1 sample: deuterium oxide. SEDFIT with the "ls-g*(s)" evaluation method was used for the calculation of the particle size distribution.

Polymerization Procedure. Polymerizations were carried out in a $500 \mathrm{~mL}$ mechanically stirred, semiautomated, stainless-steel pressure reactor equipped with a heating/cooling jacket supplied by a thermostat controlled by a temperature sensor dipping into the reaction mixture. When required, a stainless-steel sampling chamber (cf. Supporting Information) equipped with sampling vessels was connected to the bottom of the reactor and was operated via a solenoid valve.

The reaction mixture consisting of $200 \mathrm{~mL}$ of degassed water or deuterium oxide, SDS, the catalyst precursor 1-TPPTS, and optionally an additive was brought to $13{ }^{\circ} \mathrm{C}$. The reactor was immediately pressurized with ethylene while stirring the solution at $500 \mathrm{rpm}$ and heating it to $15^{\circ} \mathrm{C}$ (for details cf. Figure S38). The direct pressurizing procedure took $\sim 30 \mathrm{~s}$. Then, the mass flow control system was activated, and after $\sim 2$ min constant pressure was reached. After the reaction was finished, the stirrer was switched off, the reaction mixture was brought to $20{ }^{\circ} \mathrm{C}$, and the pressure was released over $\sim 30 \mathrm{~min}$ using a pulsed solenoid valve. Standard conditions refer to polymerization at $15{ }^{\circ} \mathrm{C}, 40$ bar.

When sampling was performed, the temperature and pressure were less constant (for details cf. Figures S37 and S38). The depressurizing of the reactor and the sampling chamber takes about $1.5 \mathrm{~h}$ to guarantee that no destabilization of the samples occurs.

\section{ASSOCIATED CONTENT}

\section{S Supporting Information}

The Supporting Information is available free of charge on the ACS Publications website at DOI: 10.1021/acs.macromol.6b01974.

Mass flow diagrams, description of the polymerization experiments and products obtained, description of the particle size analysis, ${ }^{13} \mathrm{C}$ NMR spectra, additional TEM and AFM micrographs and additional information about the sampling experiments and sampling chamber (PDF)

\section{AUTHOR INFORMATION}

\section{Corresponding Author}

*(S.M.) E-mail: stefan.mecking@uni-konstanz.de.

\section{ORCID ${ }^{\circ}$}

Alexandra Godin: 0000-0001-8136-6722

Stefan Mecking: 0000-0002-6618-6659

\section{Notes}

The authors declare no competing financial interest.

\section{ACKNOWLEDGMENTS}

A.G. is grateful to the Carl-Zeiss-Stiftung for a graduate fellowship. We thank Lars Bolk for DSC and GPC analyses, Marina Krumova for scattering experiments and TEM analysis, Dirk Haffke for AUZ measurements and Anke Friemel for the high-temperature NMR measurements. Financial support by the DFG (SFB 1214) is gratefully acknowledged.

\section{ABBREVIATIONS}

AFM, atomic force microscopy; AUZ, analytical ultracentrifuge; CsDS, cesium dodecyl sulfate; DABCO, 1,4-diazabicyclo[2.2.2] octane; DBU, 1,8-diazabicyclo[5.4.0] undec-7-ene; DLS, dynamic light scattering; DMA, $N, N$-dimethylacetamide; DMF, dimethylformamide; DMSO, dimethyl sulfoxide; DSC, differential scanning calorimetry; EELS, electron energy loss spectroscopy; HDPE, high density polyethylene; MWD, molecular weight distribution; PE, polyethylene; PSD, particle size distribution; SDS, sodium dodecyl sulfate; TEM, transmission electron mictroscopy; THF, tetrahydrofuran; TPPTS, $3,3^{\prime}, 3^{\prime \prime}$-phosphinetriyltribenzenesulfonate.

\section{REFERENCES}

(1) Caruso, F. Colloids and Colloid Assemblies; Wiley-VCH: Weinheim, Germany, 2004.

(2) Urban, D.; Takamura, K. Polymer Dispersions and Their Industrial Applications; Wiley-VCH: Weinheim, Germany, 2002.

(3) van Herk, A. M. Chemistry and Technology of Emulsion Polymerization; Blackwell Publishing: Oxford, UK, 2005.

(4) Distler, D. Wässrige Polymerdispersionen; VCH: Weinheim, Germany, 1999.

(5) Fitch, R. M. Polymer Colloids; Academic Press: San Diego, CA, 1997.

(6) Lovell, P. A.; El-Aasser, M. S. Emulsion Polymerization and Emulsion Polymers; Wiley: Chichester, UK, 1997.

(7) Stürzel, M.; Mihan, S.; Mülhaupt, R. From Multisite Polymerization Catalysis to Sustainable Materials and All-Polyolefin Composites. Chem. Rev. 2016, 116, 1398-1433.

(8) Baier, M. C.; Zuideveld, M. A.; Mecking, S. Post-metallocenes in the industrial production of polyolefins. Angew. Chem., Int. Ed. 2014, 53, 9722-9744.

(9) Kryuchkov, V. A.; Daigle, J.-C.; Skupov, K. M.; Claverie, J. P.; Winnik, F. M. Amphiphilic Polyethylenes Leading to Surfactant-Free Thermoresponsive Nanoparticles. J. Am. Chem. Soc. 2010, 132, 15573-15579.

(10) Dow Chemicals has commercialized polyolefins dispersions under the tradename HYPOD; cf. www.dowpod.com.

(11) Luo, J.; Lu, F.; Shea, K. J. Hydrocarbon Waxes from a Salt in Water: The C1 Polymerization of Trimethylsulfoxonium Halide. ACS Macro Lett. 2012, 1, 560-563.

(12) Göttker-Schnetmann, I.; Korthals, B.; Mecking, S. WaterSoluble Salicylaldiminato Ni(II)-Methyl Complexes: Enhanced Dissociative Activation for Ethylene Polymerization with Unprecedented Nanoparticle Formation. J. Am. Chem. Soc. 2006, 128, 77087709.

(13) Korthals, B.; Göttker-Schnetmann, I.; Mecking, S. Nickel(II)Methyl Complexes with Water-Soluble Ligands L $\left[\left(\kappa^{2}-\mathrm{N}, \mathrm{O}-\right.\right.$ salicylaldiminato) $\mathrm{NiMe}(\mathrm{L})]$ and Their Catalytic Properties in Disperse Aqueous Systems. Organometallics 2007, 26, 1311-1316.

(14) Yu, S.-M.; Mecking, S. Variable crystallinity Polyethylene Nanoparticles. Macromolecules 2009, 42, 3669-3673.

(15) Kolb, L.; Monteil, V.; Thomann, R.; Mecking, S. Aqueous Dispersions of Extraordinarily Small Polyethylene Nanoparticles. Angew. Chem., Int. Ed. 2005, 44, 429-432. Angew. Chem. 2005, 117, 433-436.

(16) Grau, E.; Dugas, P.-Y.; Broyer, J.-P.; Boisson, C.; Spitz, R.; Monteil, V. Aqueous Dispersions of Nonspherical Polyethylene Nanoparticles from Free-Radical Polymerization under Mild Conditions. Angew. Chem., Int. Ed. 2010, 49, 6810-6812. and references cited herein.

(17) Weber, C. H. M.; Chiche, A.; Krausch, G.; Rosenfeldt, S.; Ballauff, M.; Harnau, L.; Göttker-Schnetmann, I.; Tong, Q.; Mecking, S. Single Lamella Nanoparticles of Polyethylene. Nano Lett. 2007, 7, 2024-2029.

(18) Berkefeld, A.; Mecking, S. Deactivation Pathways of Neutral Ni(II) Polymerization Catalysts. J. Am. Chem. Soc. 2009, 131, 15651574.

(19) Unless stated otherwise, all polymerization reactions discussed in this work were performed at standard conditions, that is, $40 \mathrm{bar}$ and $15{ }^{\circ} \mathrm{C}$. 
(20) Randall, J. C. A review of high resolution liquid 13carbon nuclear magnetic resonanace characterizations of ethylene-based polymers Rev. J. Macromol. Sci., Polym. Rev. 1989, 29, 201-317.

(21) Rünzi, T.; Tritschler, U.; Roesle, P.; Göttker-Schnetmann, I.; Möller, H. M.; Caporaso, L.; Poater, A.; Cavallo, L.; Mecking, S. Activation and Deactivation of Neutral Palladium(II) Phosphinesulfonato Polymerization Catalysts. Organometallics 2012, 31, 8388-8406.

(22) Protonolysis of related salicylaldiminato nickel-methyl complexes has already been proposed by: Hristov, I. H.; DeKock, R. L.; Anderson, G. D. W.; Göttker-Schnetmann, I.; Mecking, S.; Ziegler, T. Possible Side Reactions Due to Water in Emulsion Polymerization by Late Transition Metal Complexes II Deactivation of the Catalyst by a Wacker-Type Reaction. Inorg. Chem. 2005, 44, 7806-7818.

(23) Jenkins, J. C.; Brookhart, M. Mechanistic Investigation of the Polymerization of Ethylene Catalyzed by Neutral Ni(II) Complexes Derived from Bulky Anilinotropone Ligands. J. Am. Chem. Soc. 2004, 126, 5827-5842.

(24) Waltman, A. W.; Younkin, T. R; Grubbs, R. H.; Younkin, T. R.; Grubbs, R. H. Insights into the Deactivation of Neutral Nickel Ethylene Polymerization Catalysts in the Presence of Functionalized Olefins. Organometallics 2004, 23, 5121-5123.

(25) Daucik, K. Revised Supplementary Release on Properties of Liquid Water at $0.1 \mathrm{MPa}$; The International Association for the Properties of Water and Steam: Plzeň, Czech Republic, 2011.

(26) Earnshaw, A.; Greenwood, N. N. Chemistry of the elements, 2nd ed.; Butterworth Heinemann: Oxford, UK, 1997.

(27) Kaler, E. W.; Chang, N. J. The Structure of Sodium Dodecyl Sulfate Micelles in Solutions of $\mathrm{H}_{2} \mathrm{O}$ and $\mathrm{D}_{2}$ O. J. Phys. Chem. 1985, 89, 2996-3000.

(28) Covington, A. K.; Robinson, R. A.; Bates, R. G. The ionization constant of deuterium oxide from 5 to $50^{\circ}$. J. Phys. Chem. 1966, 70, $3820-3824$.

(29) Goid, V.; Lowe, B. M. Deuterium solvent isotope effects on acid-base equilibria in dioxin-water mixtures. Proc. Chem. Soc. 1963, 140, 273-279.

(30) Osichow, A.; Rabe, C.; Vogtt, K.; Narayanan, T.; Harnau, L.; Drechsler, M.; Ballauff, M.; Mecking, S. Ideal Polyethylene Nanocrystals. J. Am. Chem. Soc. 2013, 135, 11645-11650.

(31) Frank, F. C.; Keller, A.; Bassett, D. C. Linear nucleation of polymers. Philos. Mag. 1963, 8, 1753-1787.

(32) White, J. R. Collapse of pyramidal polyethylene crystals. J. Polym. Sci., Polym. Phys. Ed. 1978, 16, 395-405.

(33) Kissin, Y. V. Polyethylene. End-Use Properties \& Their Physical Meaning; Hauser Verlag: Munich, Germany, 2013.

(34) Ranby, B. G.; Morehead, F. F.; Walter, N. M. Morphology of nalkanes, linear polyethylene, and isotactic polypropylene crystallized from solution. J. Polym. Sci. 1960, 44, 349-367.

(35) Hosier, I. L.; Bassett, D. C. A study of the morphologies and growth kinetics of three monodisperse n-alkanes: C122H246, C162H326 and C246H494. Polymer 2000, 41, 8801-8812.

(36) Lüttschwager, N. O. B.; Wassermann, T. N.; Mata, R. M.; Suhm, M. A. The Last Globally Stable Extended Alkane. Angew. Chem., Int. Ed. 2013, 52, 463-466.

(37) Keller, A. A note on single crystals in polymers: Evidence for a folded chain configuration. Philos. Mag. 1957, 2, 1171-1175.

(38) Vasile, C. Handbook of Polyolefins, 2nd ed.; CRC Press: Basel, Swizerland, 2000.

(39) Strobl, G. Crystallization and melting of bulk polymers: new observations, conclusions and a thermodynamic scheme. Prog. Polym. Sci. 2006, 31, 398-442.

(40) Caminiti, R.; Pandolfi, L.; Ballirano, P. Structure of polyethylene from X-ray powder diffraction: Influence of the amorphous fraction on data analysis. J. Macromol. Sci., Part B: Phys. 2000, 39, 481-492.

(41) With $V_{\text {total }}$ being the total volume of the polymer obtained. $V_{\text {part,mean }}$ was calculated according to $\mathrm{V}=4 / 3 \pi r_{\text {part }}^{3}$ with $r_{\text {part }}=0.5 D_{\mathrm{h}}$. The typical density of PE nanocrystals of $0.95 \mathrm{~g} \mathrm{~cm}^{-3}$ was used for the calculation of $V_{\text {total }} \cdot m_{\text {total,polymer }}$ is the polymer yield.

(42) Bartik, T.; Bartik, B.; Hanson, B. E.; Glass, T.; Bebout, W. Comments on the Synthesis of Trisulfonated Triphenylphosphine:
Reaction Monitoring by NMR Spectroscopy. Inorg. Chem. 1992, 31, $2667-2670$. 